\title{
Cardiovascular complications after acute spinal cord injury: pathophysiology, diagnosis, and management
}

\author{
Julio C. Furlan, M.D., M.B.A., M.Sc., Ph.D., 1,2 \\ and Michael G. Fehlings, M.D., Ph.D., F.R.C.S.C. ${ }^{1-3}$ \\ ${ }^{1}$ Division of Genetics and Development, Toronto Western Research Institute, University Health Network; \\ ${ }^{2}$ Spinal Program, Krembil Neuroscience Centre, Toronto Western Hospital, University Health Network; \\ and ${ }^{3}$ Division of Neurosurgery, Department of Surgery, University of Toronto, Ontario, Canada
}

\begin{abstract}
Cardiovascular complications in the acute stage following traumatic spinal cord injury (SCI) require prompt medical attention to avoid neurological compromise, morbidity, and death. In this review, the authors summarize the neural regulation of the cardiovascular system as well as the pathophysiology, diagnosis, and management of major cardiovascular complications that can occur following acute (up to 30 days) traumatic SCI. Hypotension (both supine and orthostatic), autonomic dysreflexia, and cardiac arrhythmias (including persistent bradycardia) are attributed to the loss of supraspinal control of the sympathetic nervous system that commonly occurs in patients with severe spinal cord lesions at T- 6 or higher. Current evidence-based guidelines recommend: 1) monitoring of cardiac and hemodynamic parameters in the acute phase of SCI; 2) maintenance of a minimum mean arterial blood pressure of $85 \mathrm{~mm} \mathrm{Hg}$ during the hyperacute phase (1 week after SCI); 3) timely detection and appropriate treatment of neurogenic shock and cardiac arrhythmias; and 4) immediate and adequate treatment of episodes of acute autonomic dysreflexia. In addition to these forms of cardiovascular dysfunction, individuals with acute SCIs are at high risk for deep venous thrombosis (DVT) and pulmonary embolism due to loss of mobility and, potentially, altered fibrinolytic activity, abnormal platelet function, and impaired circadian variations of hemostatic and fibrinolytic parameters. Current evidence supports a recommendation for thromboprophylaxis using mechanical methods and anticoagulants during the acute stage up to 3 months following SCI, depending on the severity and level of injury. Low-molecular-weight heparin is the first choice for anticoagulant prophylaxis in patients with acute SCI. Although there is insufficient evidence to recommend (or refute) the use of screening tests for DVT in asymptomatic adults with acute SCI, this strategy may detect asymptomatic DVT in at least $9.4 \%$ of individuals who undergo thromboprophylaxis using lowmolecular-weight heparin. Indications and treatment of DVT and acute pulmonary embolism are well established and are summarized in this review. Recognition of cardiovascular complications after acute SCI is essential to minimize adverse outcomes and to optimize recovery. (DOI: 10.3171/FOC.2008.25.11.E13)
\end{abstract}

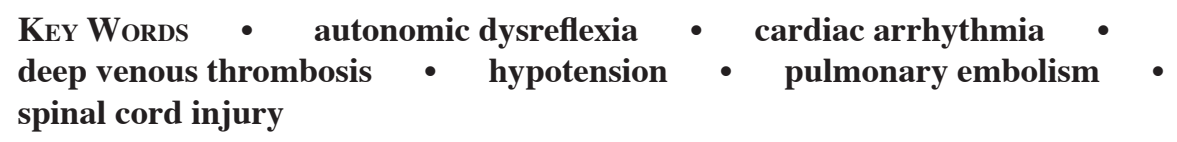

$\mathrm{S}$ PINAL cord injury may be a devastating event for individuals, who may develop motor and sensory impairment and autonomic dysfunction caudal to the level of injury. In addition, SCI represents a substantial economic burden for society, with estimated treatment costs of $\$ 9.7$ billion (2006) per year. ${ }^{17}$ The prevalence of SCI was estimated to be 280 and 681 individuals with SCIs per million inhabitants in Finland and Australia, respectively. ${ }^{23,83}$ The estimated incidence of SCI in North America varies from 27 to 81 cases per million inhabitants per year. ${ }^{107}$

Historically, renal and respiratory complications

\footnotetext{
Abbreviations used in this paper: $\mathrm{AANS}=$ American Association of Neurological Surgeons; ABP = arterial blood pressure; ANS = autonomic nervous system; CNS = Congress of Neurological Surgeons; DVT = deep venous thrombosis; ECG = electrocardiogram; $\mathrm{PE}=$ pulmonary embolism; $\mathrm{SCI}=$ spinal cord injury; $\mathrm{SNS}=$ sympathetic nervous system; VTE = venous thromboembolism.
}

have been considered to be the most frequent adverse events after SCI and the most common causes of death. ${ }^{81}$ However, more recently, cardiovascular disease has been recognized as the leading cause of death in the acute and chronic stages following SCI. ${ }^{35,39}$ Management of cardiovascular function is particularly challenging during the acute stage of SCI due to the concurrence of neurogenic shock and the common association with other traumatic injuries that can aggravate hemodynamic instability due to hypovolemia. Additionally, paralyzed patients are a well-recognized risk group for DVT and PE, especially during the acute phase following SCI.77,109

Given the clinical relevance of this topic in the acute care setting, we sought to review current knowledge on the neuroanatomy, pathophysiology, and diagnosis of cardiovascular complications, including altered blood pressure and heart rate abnormalities, as well as VTE in the acute stage (up to 30 days) following traumatic SCI. In this paper we also summarize the current evidence-based 


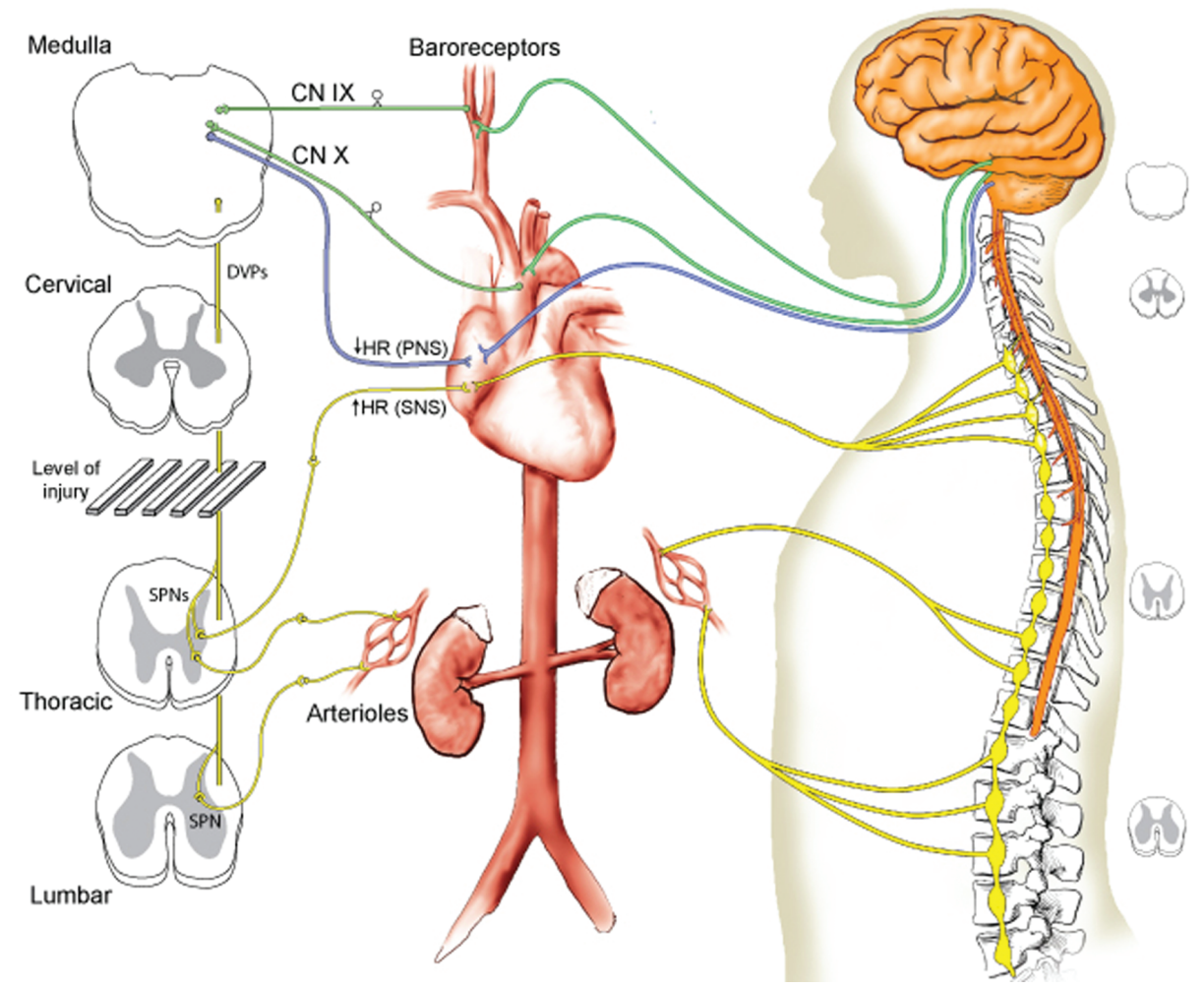

FIG. 1. Schematic representation of the central and autonomic innervation of the cardiovascular system. On the left (front view of spinal cord), the spinal sympathetic preganglionic neurons (SPNs) are shown as disconnected from the medullary cardiovascular centers by a cervical SCl, whereas the parasympathetic nervous system (PNS) is intact. Parasympathetic cardiac innervation (in blue) and sympathetic cardiac innervation (in yellow) can reduce and increase heart rate (HR), respectively. Parasympathetic afferents from baroreceptors of the aortic arch and carotid artery travel to the medulla oblongata through cranial nerves (CN) IX (glossopharyngeal nerve; in green) and X (vagus nerve; in green). Efferent fibers are denoted by yellow or blue lines, afferent fibers by green lines. The right-sided figure schematically depicts the neuroanatomy of the cardiovascular innervation including central nervous system (orange), extramedullary SNS (yellow), and extramedullary PNS (blue). DVPS = descending vasomotor pathways.

guidelines for the management of major cardiovascular complications after acute SCI.

\section{Innervation of the Cardiovascular System}

The neural regulatory mechanisms of the cardiovascular system are summarized in Fig. 1.

\section{Supraspinal Control of the Cardiovascular System}

In the brain, a complex neural circuitry in the hypothalamus receives afferent inputs from many brain regions, finely processes them, and eventually modulates the cardiovascular response to different stimuli. There are at least 2 key hypothalamic regions that are involved in cardiovascular control-the dorsomedial hypothalamus and the paraventricular nucleus. ${ }^{22,48}$ Whereas sympathetic premotor neurons-which project directly to sympathetic preganglionic neurons in the spinal cord-are found in the paraventricular nucleus, they are reportedly missing in the dorsomedial hypothalamus where synapses with sympathetic premotor neurons occur at the supraspinal levels..$^{22,48}$ Descending pathways mediating sympathetic influences from the dorsomedial hypothalamus originate in different groups of sympathetic premotor neurons that are reportedly located in the rostral ventrolateral medulla and raphe pallidus. ${ }^{73,96}$ Activation of neurons in the dorsomedial hypothalamus evokes a variety of responses including increased activity of sympathetic nerve activity in the heart, kidney, and other organs. ${ }^{16,31}$ Sympathetic vasomotor activation mainly through the rostral ventrolateral medulla (and slightly via the raphe pallidus) results in an increase in ABP, whereas sympathetic cardiac activation largely via the raphe pallidus (and slightly through direct influence from the dorsomedial hypothalamus) causes an increase in heart rate. ${ }^{48}$ Central serotonin $1 \mathrm{~A}$ receptors and $\gamma$-aminobutyric acid, which were identified in both rostral ventrolateral medulla and raphe pallidus medullary areas, are deemed to be critical in the modulation of the cardiovascular response to various stimuli. ${ }^{77,82,89}$

In addition to the activity of the dorsomedial hypothalamus neurons, the inputs of the paraventricular nucleus neurons, adjacent to the third ventricle, in the hypothalamus are of great importance for cardiovascular regulation..$^{22}$ The vagus nerve (cranial nerve $\mathrm{X}$ ), which is the afferent pathway to the brain for atrial volume receptors, has its first synapse in the nucleus tractus solitarius of the medulla oblongata. ${ }^{59}$ Inputs from the nucleus tractus solitarius evoke the neuronal activity of the para- 


\section{Cardiovascular complications in the acute stage after SCI}

ventricular nucleus, including magnocellular peptidergic neurohypophyseal neurons that secrete oxytocin and vasopressin. ${ }^{22,71,87}$ Previous studies have suggested that vasopressin neurons projecting to the spinal cord from the paraventricular nucleus exert an excitatory influence on renal sympathetic preganglionic neurons and are tonically inhibited by a network of $\gamma$-aminobutyric acid neurons in the paraventricular nucleus. ${ }^{22}$ Moreover, response to plasma volume signals has been associated with activation of the early gene $c$-fos in several parvocellular neurons that project to sites in the spinal cord and brainstem involved in cardiovascular regulation. ${ }^{11,24,86,87,93}$ Stimulation of various sites within the paraventricular nucleus subnuclei has been shown to increase heart rate via activation of paraventricular nucleus oxytocin pathways projecting to the spine. ${ }^{108}$ Also, electrophysiological studies have indicated that oxytocin elicits an excitatory response of sympathetic preganglionic neurons in the upper thoracic spinal cord of rats and affects the activity of sympathetic preganglionic neurons in the lower thoracic cord..$^{25,92}$

Previous experimental studies in rats indicate that stimulation of cardiac vagal afferents or circulating atrial natriuretic peptide activates some paraventricular nucleus neurons projecting to the spine, whereas others are inhibited..$^{70-72}$ Whereas plasma volume expansion or selective stimulation of venous-atrial junctions reportedly causes a sympathetically mediated increase in heart rate in dogs and rodents, it results simultaneously in a decrease in sympathetic activity to the kidneys and renal vasodilation, as well as increased urine flow and sodium loss. ${ }^{12,52-}$ $55,60,87$ Therefore, there is evidence to strongly indicate that the paraventricular nucleus is a "command center" for the atrial (volume) reflex with paraventricular nucleus cardiac and renal arms as described above.22

\section{Contribution of the Spinal Cord and ANS to Cardiovascu- lar Control}

The ANS plays a crucial role in the cross talk between the brain and the cardiovascular system to maintain an immensely complex dynamic equilibrium of the internal milieu (or homeostasis). ${ }^{28}$ The SNS and parasympathetic nervous system are the 2 divisions of the ANS that integrate complex reflex pathways including sensory receptors, afferent pathways, integration centers in the central nervous system (as noted above), efferent pathways, and target organs (Fig. 1). ${ }^{79}$

Sympathetic afferents originating in ergoreceptors (mechanoreceptors) in skeletal muscles, arterial chemoreceptors, and cardiopulmonary receptors provide excitatory input to the nucleus tractus solitarius. ${ }^{27}$ Parasympathetic afferents, originating in baroreceptors of the aortic arch and carotid artery, and receptors of the systemic and pulmonary vessels, the great veins, and the atria provide inhibitory input to the nucleus tractus solitarius via the vagus nerve and glossopharyngeal nerve (Fig. 1). ${ }^{43}$

The efferent pathways in both divisions of the ANS include preganglionic and postganglionic neurons. The preganglionic neurons are interneurons that originate centrally, trasverse the ventral roots, and terminate in an ANS ganglion outside the central nervous system. The postganglionic neurons are effector neurons that originate in the ANS ganglion and terminate in an effector organ such as the heart and blood vessels. Whereas the cell bodies of the preganglionic neurons are located in the brain or spinal cord, the cell bodies of the postganglionic neurons lie in autonomic ganglia that are located near the spinal cord or the effector organ. ${ }^{40}$ Sympathetic preganglionic fibers may synapse in the paravertebral ganglia of the sympathetic chain, which are located laterally to the vertebral bodies or close to the viscera in prevertebral ganglia. ${ }^{9} \mathrm{Al}-$ though all sympathetic preganglionic neurons synapse in the sympathetic chain, which includes the superior cervical ganglion, middle cervical ganglion, stellate ganglion, and thoracic paravertebral ganglia in the regions cranial to the diaphragm, ${ }^{40}$ the sympathetic preganglionic fibers to the abdomen and pelvis cross the paravertebral ganglia without synapses to form splanchnic nerves. ${ }^{40}$ The latter fibers synapse with sympathetic postganglionic fibers in collateral ganglia prior to joining major arteries on their way to the effector organs. ${ }^{40}$ Sympathetic outflow to the effectors in the splanchnic region mostly originates from T-5 to T-9, which forms the greater splanchnic nerve to the celiac ganglion. ${ }^{40}$ The postganglionic neurons of the SNS also form visceral nerves (e.g., cardiac nerves) and innervate blood vessels and skin. ${ }^{40}$

Both sympathetic and parasympathetic inputs influence functions of the heart. The cardiac sympathetic preganglionic neurons exit the spinal cord from $\mathrm{T}-1$ to T-6 to synapse with cardiac sympathetic postganglionic neurons in the middle cervical ganglion and stellate ganglion. ${ }^{13}$ The parasympathetic neurons from the dorsal motor nucleus of the vagus and the nucleus ambiguous in the medulla oblongata reach the heart via recurrent laryngeal nerves and the vagus nerve. ${ }^{69}$ Parasympathetic neurons synapse with postganglionic cells localized in the epicardium or within the cardiac walls adjacent to the sinoatrial or atrioventricular node..$^{40}$ Clinically, hyperstimulation of the right vagus nerve makes the heart susceptible to bradyarrhythmias, whereas hyperstimulation of the left vagus nerve predisposes the heart to atrioventricular blocks.

\section{Pathophysiology of Cardiovascular Complications Following SCI}

\section{Cardiovascular Dysfunction After Supraspinal Decentral- ization}

The intact spinal cord is required for suitable autonomic control of different viscera and organs, including the heart and blood vessels. The degree of sympathetic cardiovascular dysfunction is directly related to the location and severity of SCI. The relationship between cardiovascular dysfunction and severity of injury was shown in several clinical studies and in a postmortem examination of human spinal cord tissue, in which individuals with cervical SCI who developed severe hypotension, bradycardia, and episodes of autonomic dysreflexia in the acute stage postinjury had significantly more extensive areas of degeneration within the spinal cord white matter a few segments caudal to the injury site in comparison with individuals with cervical SCI without significant cardiovascular dysfunction (Figs. 2 and 3). ${ }^{37,62}$ 
J. C. Furlan and M. G. Fehlings

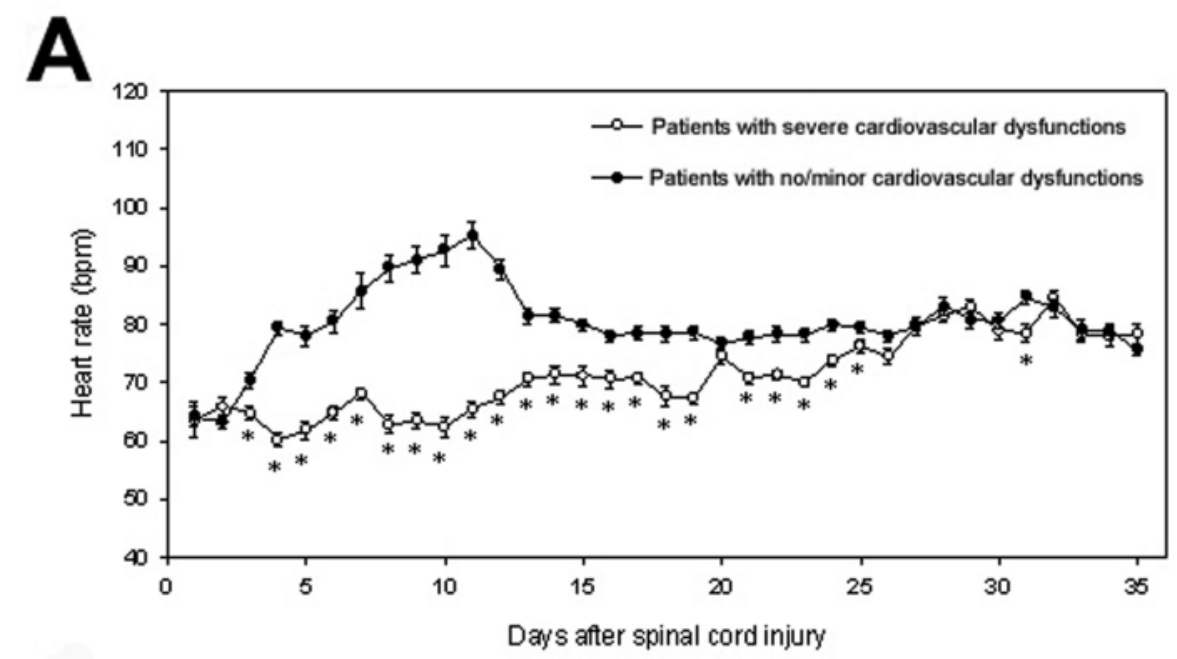

B

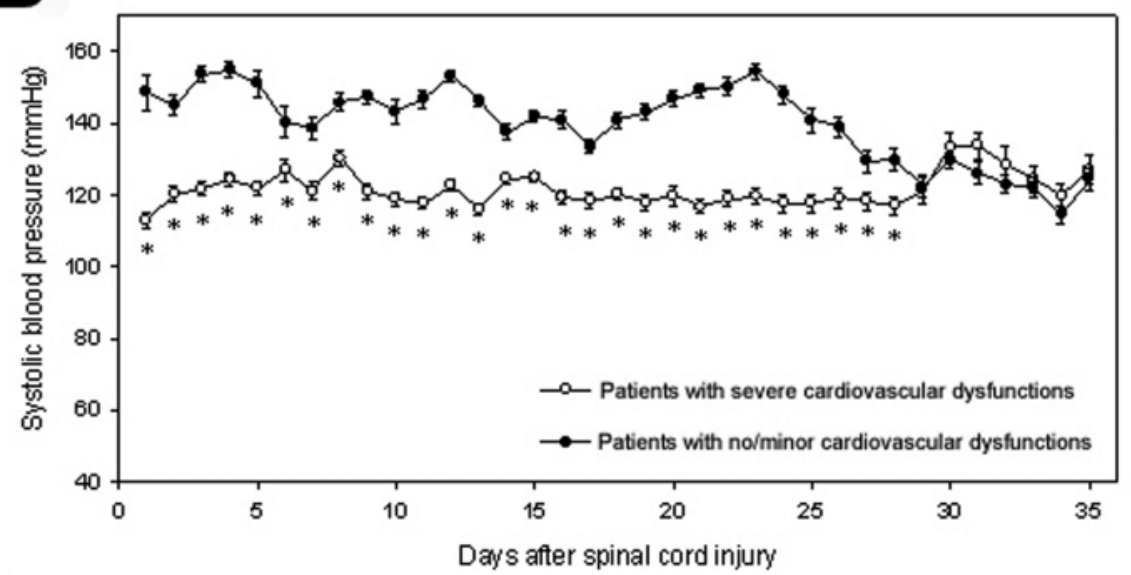

C

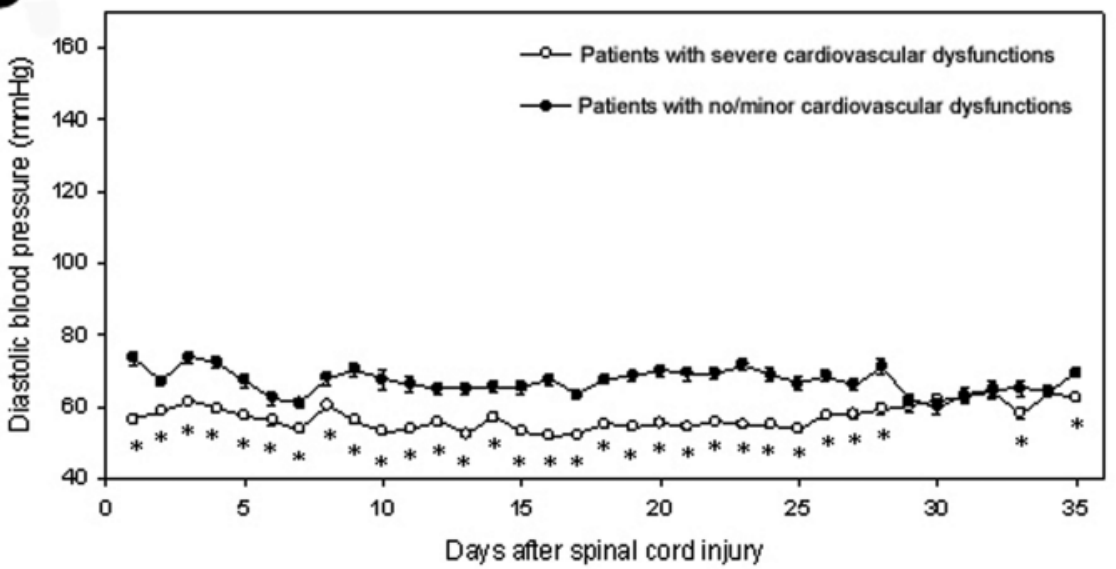

FIG. 2. Graphs showing parameters of neurogenic shock following acute traumatic cervical SCI in two groups of patients. Hemodynamic and cardiac parameters in patients with $\mathrm{SCl}$ are categorized as severe cardiovascular dysfunction as opposed to $\mathrm{no} /$ minor cardiovascular dysfunction. Mean values ( \pm standard error of the mean) of heart rate $(\mathrm{A})$ and systolic $(\mathrm{B})$ and diastolic (C) blood pressures within the first 5 weeks following $\mathrm{SCl}$ are shown. Asterisks indicate significant differences between both groups of patients. Bpm = beats per minute. Adapted with permission from Furlan JC, Fehlings MG, Shannon P, et al: Descending vasomotor pathways in humans: correlation between axonal preservation and cardiovascular dysfunction after spinal cord injury. J Neurotrauma 20:1351-1363, 2003. 


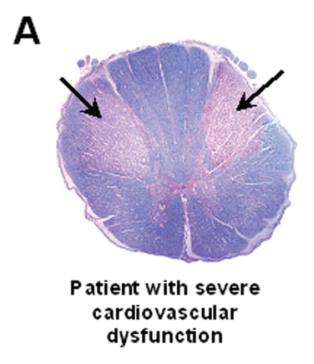

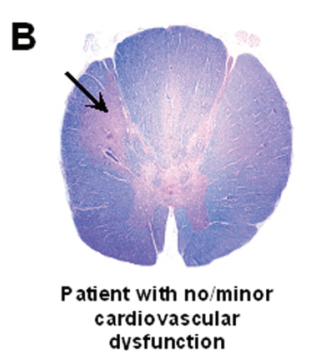

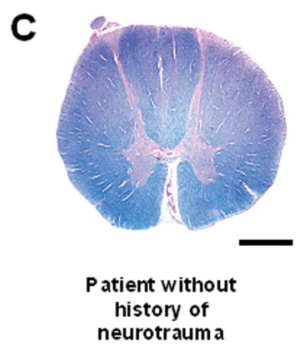

D

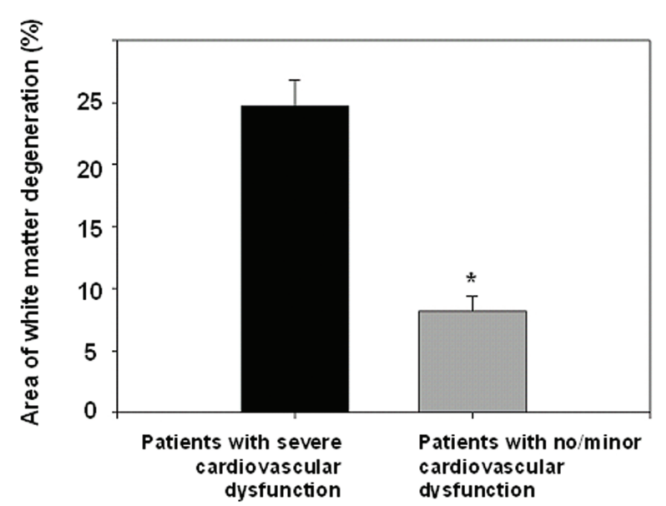

FIG. 3. Sections of spinal cord tissue (A-C) and graph (D) demonstrating the association between cardiovascular dysfunction and severity of SCl. A-C: High-thoracic spinal cord sections stained for myelin with Luxol fast blue include a representative case of severe cardiovascular dysfunction in the acute stage after $\mathrm{SCl}(\mathrm{A})$, a representative case without significant cardiovascular dysfunction following SCI (B), and a representative control case without neurotrauma (C). A well-defined butterfly-shaped area of gray matter can be observed in all sections. Myelin-containing white matter is stained blue. In sections from cases of $\mathrm{SCl}(\mathrm{A}$ and B), there are areas of axonal degeneration and myelin loss (pink areas within the white matter, indicated by arrows). Bar $=2 \mathrm{~mm}$. D: Graph shows that there was a significant increase in total area of white matter degeneration (expressed as a percentage of the total spinal cord area) in sections of the spinal cords in individuals with severe cardiovascular dysfunction after SCl, compared with individuals without significant cardiovascular dysfunction following SCl. Adapted with permission from Furlan JC, Fehlings MG, Shannon P, et al: Descending vasomotor pathways in humans: correlation between axonal preservation and cardiovascular dysfunction after spinal cord injury. J Neurotrauma 20:1351-1363, 2003.

Cervical or high-thoracic (T-6 or above) severe SCI deprives patients of supraspinal sympathetic control of cardiovascular functions that include coronary blood flow, cardiac contractility, and heart rate. ${ }^{40}$ In this group of patients with SCI, parasympathetic cardiac responses via the vagus nerve are the only supraspinal control of the heart, leading to bradycardia and other cardiac arrhythmias. Partial sympathetic denervation of the heart evokes milder cardiovascular dysfunctions in individuals with minor SCI and injuries between T-1 and T- $6 .{ }^{40}$ Although normal cardiovascular responses can occur in patients with an SCI caudal to the T-6 level, abnormal peripheral vasomotor responses due to decentralized regulation of vascular tone and blood pressure control are seen in patients with severe SCI at T-6 or a more cranial injury who develop low resting blood pressure, orthostatic hypotension, and loss of diurnal fluctuation of blood pressure.$^{40}$ In addition to those blood pressure abnormalities, patients with a severe SCI at T-6 or a more cranial injury can experience episodes of autonomic dysreflexia, which is characterized by a sudden increase in blood pressure when a triggering event occurs. ${ }^{62}$

Although the pathophysiology of abnormal cardiovas- cular control in patients with acute SCI is not completely understood, at least 5 elements of the autonomic circuits have been identified as potentially contributing factors: 1) disruption of the descending cardiovascular (or vasomotor) pathways; 2) morphological changes in the cardiac and vasomotor sympathetic preganglionic neurons; 3) sprouting and the potential formation of inappropriate synapses with spinal interneurons; 4) abnormal spinal efferents; and 5) development of altered sympathetic neurovascular transmission and smooth muscle responsiveness. Given that many of those anatomical changes occur only in the subacute or chronic stages following SCI, the disruption of the descending cardiovascular (or vasomotor) pathways is the most evident contributing factor for the abnormal cardiovascular control observed during the acute stage after severe SCI at T- 6 or a more cranial level.

Disruption of these sympathoexcitatory pathways has been associated with several cardiovascular abnormalities in the acute postinjury stage in experimental studies and in a clinicopathological human study. ${ }^{32,37,58}$ In an immunohistochemical examination of postmortem spinal cord tissue, individuals who developed severe hypoten- 
J. C. Furlan and M. G. Fehlings

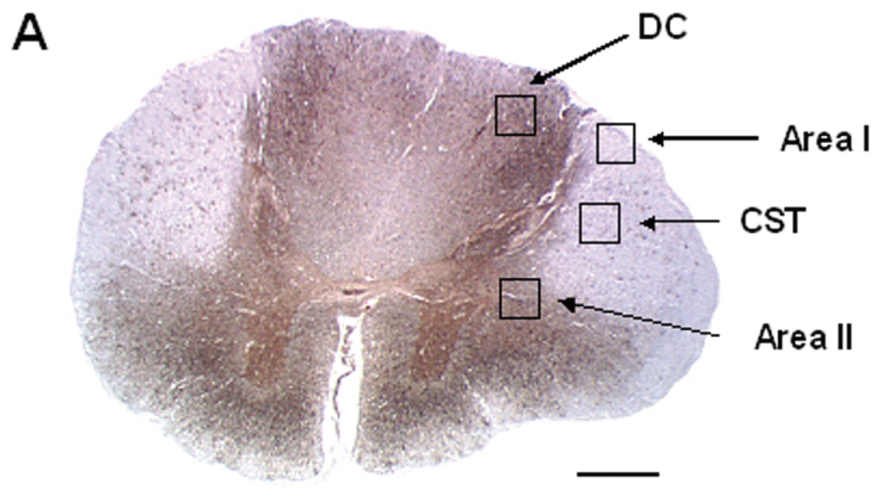

B

\section{Patient with severe cardiovascular dysfunction}

DC

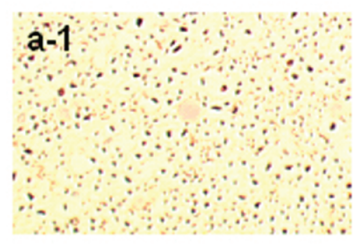

b-1

Area I
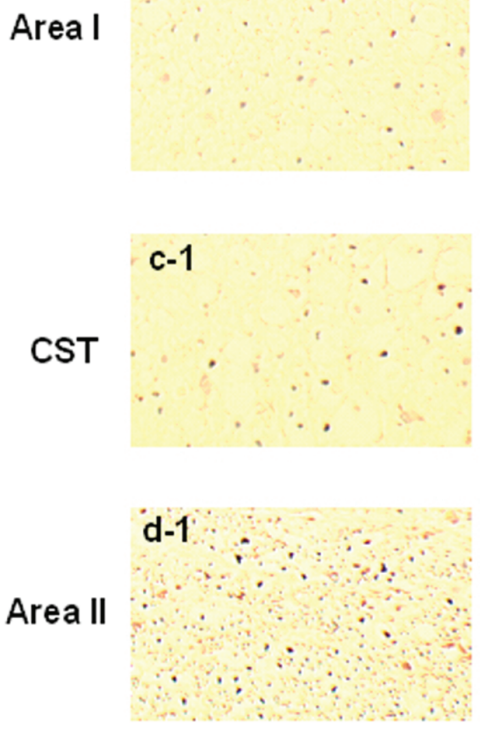

Patient with no/minor cardiovascular dysfunction
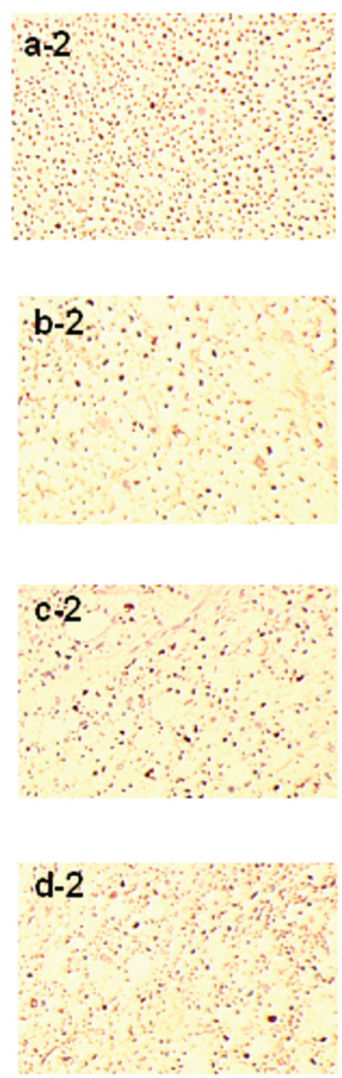

Patient without history of neurotrauma
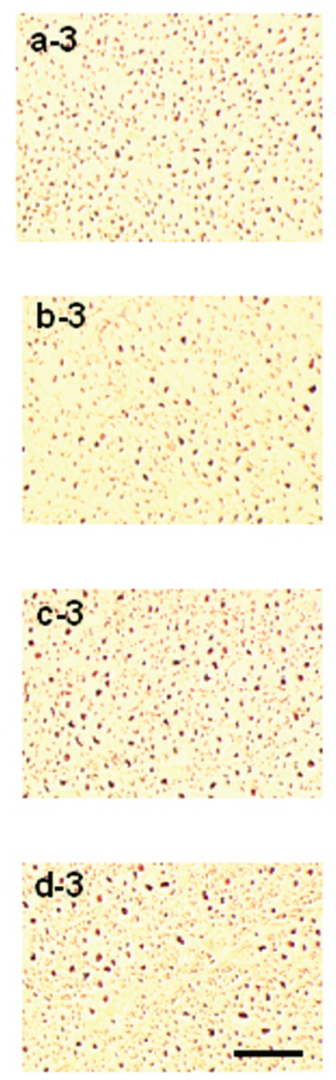

FIG. 4. Images showing the localization of descending vasomotor (cardiovascular) pathways in humans. A: Spinal cord section under low power magnification $(\times 1.25)$ that was immunostained for neurofilament 200 to identify axons from an individual who developed severe cardiovascular dysfunction during the acute stage after SCl. Areas of the spinal cord where counting of the preserved axons was conducted are marked by squares that include: dorsal column (DC), Area I, lateral corticospinal tracts (CSTs), and Area II. Bar = $1 \mathrm{~mm}$. B: High magnification $(\times 20)$ of different areas of the spinal cord stained with neurofilament 200 from a representative case of severe cardiovascular dysfunction after $\mathrm{SCl}$, a case of $\mathrm{SCl}$ without significant cardiovascular dysfunction, and a control case without a history of central nervous system trauma. The brown-stained dots represent cross-sections of spinal axons immunocytochemically identified with neurofilament 200. There was a significant axonal loss within Area 1 (panel b-1) and the CST (panel c-1) in all individuals with severe cardiovascular dysfunction following SCI. Bar $=50 \mu \mathrm{m}$, for all panels in B. Adapted with permission from Furlan JC, Fehlings MG, Shannon P, et al: Descending vasomotor pathways in humans: correlation between axonal preservation and cardiovascular dysfunction after spinal cord injury. J Neurotrauma 20:1351-1363, 2003. 


\section{Cardiovascular complications in the acute stage after SCI}

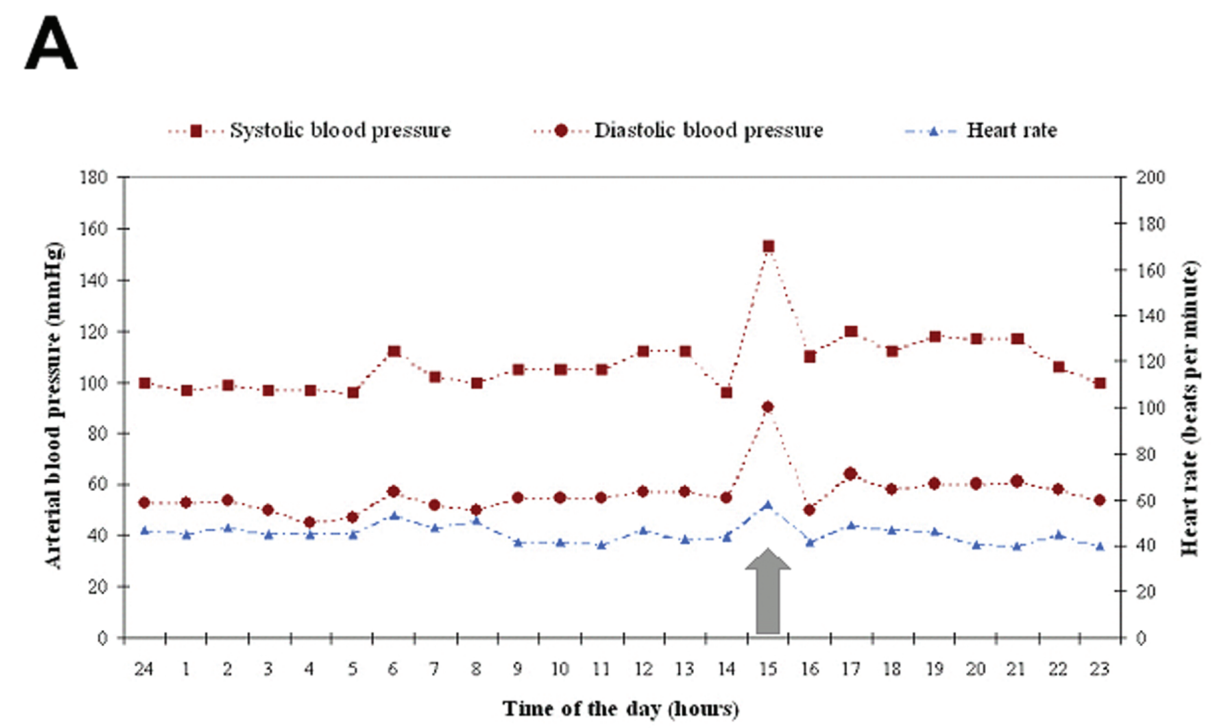

B

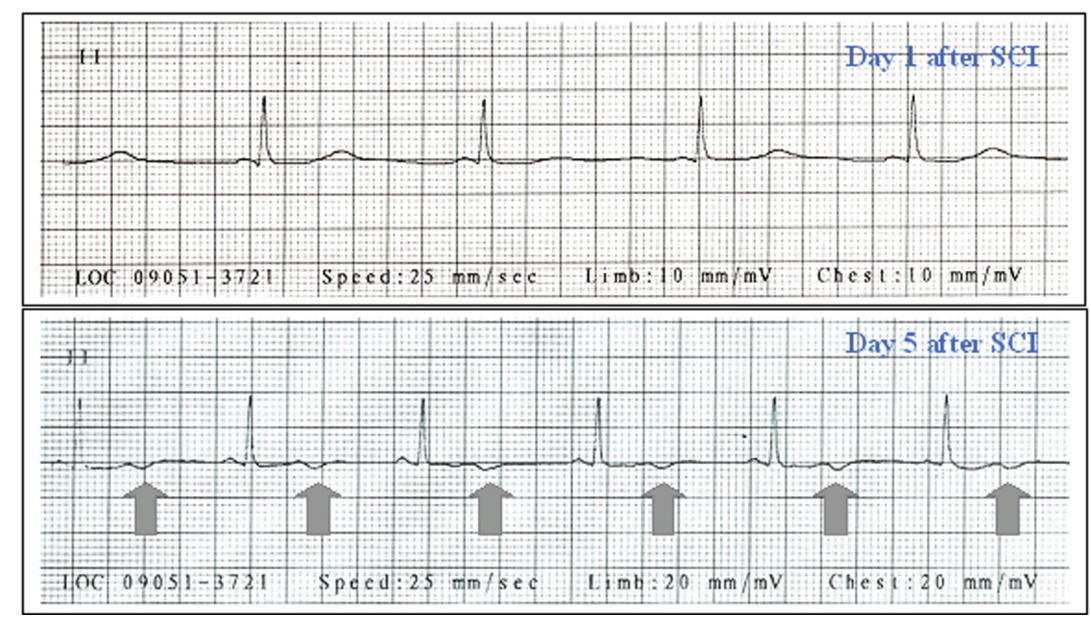

FIG. 5. Graphs showing characteristics of an early episode of autonomic dysreflexia and ECG abnormality after acute cervical SCl. A: The 24-hour blood pressure and heart rate records at Day 4 after a $\mathrm{C} 2-3$, motor and sensory complete SCl obtained in a 31-year-old woman due to a diving accident shows an episode of hypertension coinciding with a full bladder (gray arrow), which was diagnosed as autonomic dysreflexia. Both blood pressure and heart rate decreased when the bladder was emptied and the position of the patient was changed. B: Graph of the ECG recordings (Lead II) at Days 1 and 5 after the accident show sinus bradycardia and, at Day 5, inverted T waves (gray arrows).

sion, bradycardia, and autonomic dysreflexia during the acute stage after cervical SCI showed significantly fewer preserved axons within the dorsal aspects of the lateral funiculi (Area I) of spinal cord sections a few segments caudal to the injury site, in comparison with individuals who presented no significant signs and symptoms of abnormal cardiovascular control (Figs. 2 and 4).

Sympathetic decentralization leads to altered regulation of the autonomic function with numerous clinical consequences, regardless of the intact parasympathetic (vagal) afferent and efferent pathways in patients with SCI. ${ }^{40}$ Pronounced hypotension and persistent bradycardia, which are commonly observed in patients with acute severe SCI at cervical or high-thoracic levels, are key components of neurogenic shock..$^{10}$ The effects of neurogenic shock are reportedly more intense and long lasting in humans (up to 5 weeks) following acute SCI (Fig. 2) in comparison with experimental animals in studies using SCI models. ${ }^{37,61}$ Of note, neurogenic shock in the acute phase of SCI should be distinguished from "spinal shock," which is characterized by a marked reduction or abolition of somatic and/or reflex functions of the spinal cord caudal to the injury site with a duration from days to 6 weeks postinjury. ${ }^{26}$

\section{Predisposition to Thromboembolic Events After SCI}

Venous thromboembolism, including DVT and PE, is another important cardiovascular complication that is 
especially common in patients with acute SCI.77,109 Although the mechanisms underlying the elevated risk for VTE among patients in the acute stage after SCI have not been completely clarified, the 3 major reasons for development of VTE (stasis, hypercoagulability, and intimal injury) can occur in patients with acute SCI. 1,77,78,109 Immobility is a major risk factor for VTE, particularly in tetraplegic patients. Given that the susceptibility to VTE after SCI declines with time, other underlying mechanisms for the development of VTE have been suggested, such as altered fibrinolytic activity, abnormal platelet function, and impaired circadian variations of hemostatic and fibrinolytic parameters. ${ }^{34,50,106}$ Of note, some patients develop spasticity, which may improve the blood perfusion of the extremities and thereby prevent thrombus formation, but spasticity does not satisfyingly explain the decreased frequency of VTE in the vast majority of patients with chronic SCI when compared with the first 3 months postinjury. ${ }^{50}$

The paucity of studies precludes an in-depth analysis of the pathophysiology of VTE during the acute stage after SCI. Previous studies indicated that the blood platelet count is reduced within the 1st week following SCI but gradually increases with time and reaches maximum levels between 2 and 3 weeks after SCI. ${ }^{34,38}$ In addition, the mean blood platelet counts among patients who developed DVT as assessed by the radiofibrinogen uptake test in the acute stage after SCI did not significantly differ from individuals with SCIs without DVT. ${ }^{34}$ In a case series of patients with paraplegia, Rossi et al ${ }^{88}$ reported that platelet aggregation response to collagen was hyperactive by Day 6 after acute SCI, whereas the platelet aggregate ratio did not become abnormal until after DVT was diagnosed. Additionally, markedly increased factor VIII antigen and ristocetin cofactor activity, as well as only slightly increased factor VIII coagulation activity, preceded the detection of DVT within the 1st month following SCI ${ }^{88}$ Fujii and colleagues $^{34}$ also reported that patients who developed DVT within the first 30 days after SCI had significantly higher blood concentrations of fibrinopeptide A, thrombin-antithrombin III complexes, and D-dimer (a fragment of fibrin) in comparison with individuals with acute SCIs without DVT. In contrast, there were no significant differences between the two patient groups with regard to other molecular markers of hemostasis activation, including blood concentrations of platelet factor 4 , fibrinogen, and $\beta$-thromboglobulin. ${ }^{34}$ Given that liver, spleen, and bone marrow are also innervated by the SNS under supraspinal control, the potential effects of acute severe SCI on coagulation function and hematopoiesis obviously require further research. ${ }^{28,38,80}$

\section{Major Cardiovascular Complications in the Acute Stage Following SCI}

\section{Orthostatic Hypotension}

Low resting blood pressure and orthostatic hypotension more often occur in patients with severe SCI at the cervical or high-thoracic level. ${ }^{75,76}$ Because of the reduced sympathetic outflow to the cardiovascular system, low resting blood pressure can be profound during the acute stage after SCI when neurogenic shock arises, but it can also be prolonged into the chronic stage postinjury. ${ }^{76}$ Orthostatic hypotension represents an additional drop in ABP when a patient with SCI is positioned upright, especially during the acute stage of SCI ${ }^{75}$ The mechanisms underlying orthostatic hypotension are incompletely understood, even though the evidence suggests that a combination of factors may be involved, including: 1) excessive pooling of blood in the organs and viscera due to reduced efferent sympathetic nervous activity and loss of the reflex vasoconstrictor effect of arterial baroreceptors caudal to the level of injury; 2) lack of the counteracting muscular effects of the lower extremities to venous pooling; 3) reduced plasma volumes as a consequence of hyponatremia; and 4) cardiovascular deconditioning as a result of prolonged bed rest. . $^{33,75,101,102}$

In a prospective case series, orthostatic hypotension (defined as a reduction in the baseline systolic blood pressure of at least $20 \mathrm{~mm} \mathrm{Hg}$ or baseline diastolic blood pressure of at least $10 \mathrm{~mm} \mathrm{Hg}$ after an orthostatic maneuver) occurred in $74 \%$ of the orthostatic maneuvers by physiotherapists during treatment of patients with acute SCI, but signs and symptoms accompanied the blood pressure changes in only $59 \%$ of the orthostatic maneuvers. ${ }^{49}$ In addition, signs and symptoms were perceived as limiting physiotherapy in one-third of orthostatic maneuvers during treatment of patients with acute SCI ${ }^{49}$ Blurred vision, light-headedness, dizziness, fatigue, restlessness, and dyspnea are among the signs and symptoms of orthostatic hypotension that have been attributed to cerebral hypoperfusion. ${ }^{18,33,91}$ Although orthostatic hypotension is usually more pronounced in the acute phase following SCI and improves over time, there is evidence that symptomatic episodes of orthostatic hypotension can persist for years after SCI in some patients. ${ }^{33}$

In addition to those predisposing factors related to hypotension following SCI, the timing of surgical decompression of the spinal cord may play an important role in the development of cardiovascular dysfunction. In a retrospective study using data from the Sygen randomized controlled trial, Tuli and colleagues ${ }^{99}$ found that the presence of neurogenic shock (systolic blood pressure lower than $90 \mathrm{~mm} \mathrm{Hg}$ ) was associated with a delay in the timing of surgical intervention in patients with cervical motor complete SCI. Those results on neurogenic shock appear to match the preliminary results of the Surgical Treatment for Acute Spinal Cord Injury Study (STASCIS), in which improved motor and sensory recovery was noted in the group of patients who underwent early surgical decompression (within the first 24 hours after SCI) in comparison with patients who underwent delayed surgical intervention. ${ }^{30,99}$ Obviously, further research is needed to examine the potential cause and effect relationship between the timing of surgical intervention and the development of neurogenic shock, because those significant differences reported by Tuli and colleagues could be accounted for by a delay in surgical intervention due to the presence of hemodynamic instability.

\section{Autonomic Dysreflexia}

In addition to neurogenic hypotension, patients with 


\section{Cardiovascular complications in the acute stage after SCI}

acute SCI at cervical or high-thoracic levels (at T-6 or a more cranial level) may experience sudden episodes of extreme elevated blood pressure accompanied by other signs and/or symptoms of autonomic overactivity in response to noxious or nonnoxious stimuli below the level of injury (so called "autonomic dysreflexia"). ${ }^{76,98}$ More specifically, severe autonomic dysreflexia can be defined as "an increase in systolic blood pressure of at least $20 \%$ associated with a change in heart rate and accompanied by at least one of the following signs (sweating, piloerection, facial flushing), or symptoms (headache, blurred vision, stuffy nose)." ${ }^{\prime 2}$ Some clinicians have also suggested that the presence of a triggering factor for a severe episode of autonomic dysreflexia, such as bladder distension or bowel impaction, should be identified for the diagnosis of this condition. ${ }^{76,98}$ Whereas severe autonomic dysreflexia raises significant clinical concerns, mild episodes of autonomic dysreflexia in response to various stimuli can occur without being noticed and may be of little clinical relevance. ${ }^{74}$ For instance, asymptomatic paroxysmal hypertension was reported in men with SCI during bladder contractions and voiding. ${ }^{68}$

Autonomic dysreflexia is a relatively common cardiovascular complication in the chronic stage, but there is evidence that episodes of autonomic dysreflexia can also occur during the acute phase postinjury. ${ }^{62,66,94}$ In a case series of 58 patients with acute SCIs treated in the Toronto Western Hospital Spinal Program, the frequency of autonomic dysreflexia in the acute stage following SCI was $5.2 \%$ (3 of 58 patients), whereas the adjusted incidence for the population at risk (SCI at T-6 or above) was $5.7 \%$ ( 3 of 53 patients). ${ }^{62}$

It is worthwhile to emphasize that the resting systolic and diastolic blood pressures in these patients with acute SCIs is lower than in able-bodied individuals and, therefore, an elevation of $20 \%$ in the baseline blood pressure that could be considered virtually within the normal range for able-bodied individuals can be life-threatening for patients with acute SCI. In Fig. 5A the cardiovascular signs of an early episode of autonomic dysreflexia can be seen during 1-day records (at Day 4 after the accident) of blood pressure and heart rate from the medical chart of a 31-year-old female patient who sustained a severe fracture at C2-3 after diving into shallow water. The episode of hypertension was accompanied by headache and blurred vision, which coincided with a full bladder; cardiovascular parameters decreased when her bladder was emptied and her position was changed.

\section{Heart Rate Abnormalities}

It is well recognized that acute SCI can provoke altered cardiac electrophysiology and increase susceptibility to cardiac arrhythmias. Sinus bradycardia (a heart rate $<50$ beats per minute) is the most common heart rate abnormality in patients in the acute stage following SCI (Fig. 5.B). However, various other irregularities in cardiac rhythm and conduction have been attributed to autonomic instability following SCI, including repolarization changes, atrioventricular blocks, supraventricular tachycardia, ventricular tachycardia, and primary cardiac arrest. ${ }^{51,64,85,105}$ Similar to the altered blood pressure con- trol after SCI, development of heart rate abnormalities in patients with acute SCI is associated with severe injury at the cervical or high-thoracic level. ${ }^{64,85,105}$ Also, the most pronounced changes are observed during the acute phase (ranging from 2 to 6 weeks postinjury), whereas heart rate parameters can improve substantially in the chronic stage. . $^{37,64,85}$

Numerous experimental and clinical studies have demonstrated the association between heart rate abnormalities and loss of supraspinal sympathetic control of the heart. ${ }^{14,19,29}$ Using a model of SCI in monkeys, Evans and colleagues ${ }^{29}$ reported sinus and atrioventricular nodal bradycardia as the immediate response to spinal cord compression as seen in ECG recordings. Subsequently, the animals presented with a variety of alterations in cardiac rhythm and conduction, which included premature atrioventricular nodal or ventricular beats, atrioventricular dissociation, ventricular tachycardias, and bigeminal and trigeminal rhythms. ${ }^{29}$ In humans, individuals with more severe SCI and fewer preserved axons within the dorsal aspects of the lateral funiculi (where descending sympathoexcitatory vasomotor pathways are located) showed significantly lower mean heart rates within the first 4 weeks following cervical SCI in comparison with individuals who sustained a less severe injury at the cervical level (Figs. 2-4). ${ }^{37}$ Using the analysis of heart rate variability in patients with acute SCI and able-bodied individuals, Bunten and colleagues ${ }^{14}$ demonstrated that both power and amplitude in the low- frequency analyses were reduced in patients with tetraplegia in comparison with healthy controls, whereas both groups did not significantly differ with regard to mean power and amplitude in the high frequency. Their results on the low and high frequency analyses indicated a loss of sympathetic tone and intact parasympathetic tone in the patients with acute cervical SCI. ${ }^{14}$

\section{Venous Thromboembolism}

Without prophylaxis, the frequency of DVT and PE in patients with acute SCI reportedly varied from 12 to $64 \%$ when the diagnosis was only based on clinical criteria. ${ }^{36}$ In a prospective study in which screening for DVT was performed in the lower extremities within the first 3 weeks after hospital admission using serial impedance plethysmography and contrast venography, 21 (81\%) of 26 individuals with acute traumatic SCI, who did not receive thromboprophylaxis, were diagnosed with DVT. ${ }^{41}$ Despite advances in the prevention of VTE with evidence-based recommendations for the use of pharmacological thromboprophylaxis in almost all patients during the acute stage after SCI, VTE still represents a potentially life-threatening condition for patients with acute SCI, with a mortality rate of $9.7 \%$ during the first year after the injury. ${ }^{36}$

Several diagnostic strategies have been developed for suspected DVT in different patient groups. Contrast venography of the lower limbs is considered the gold standard for diagnosis of DVT, but its invasive nature, potential complications, technical issues, and costs preclude venography from being used routinely. ${ }^{36}$ Duplex ultrasonography has become the imaging test of choice to diagnose DVT in the clinical setting, even though its 
relatively low sensitivity for proximal imaging (29\%) and for both proximal and distal imaging (18.2\%) in patients in the acute stage after SCI is a matter of concern. ${ }^{7,36,90}$ In a recent systematic review, Orbell and colleagues ${ }^{84}$ indicated that CT or MR venography could overcome the limitations of the ultrasonographic diagnosis of DVT, but further technical refinement is required prior to their use in clinical practice. Impedance plethysmography can be used to diagnose DVT by detecting increased venous outflow resistance in the deep veins of the lower limbs, but its use has been discontinued in many centers due to its relatively low sensitivity for detecting proximal-vein DVT (66\%). ${ }^{36}$ Nuclear medicine techniques such as ${ }^{111} \mathrm{In}-$ labeled platelet scintigraphy, ${ }^{99 \mathrm{~m}} \mathrm{Tc}-$ labeled platelet glycoprotein IIb/IIIa receptor antagonist, and ${ }^{125}$ I-labeled fibrinogen are not currently used in clinical practice because they are costly and are not advantageous in terms of accuracy in comparison with other diagnostic tests. ${ }^{84}$ The use of radiolabeled fibrinogen has also been limited due to concerns over the safety of injecting blood-derived products. ${ }^{36}$ Duplex ultrasonography, impedance plethysmography, and venography were considered as practice options - reflecting unclear clinical certainty-in the imaging diagnosis of DVT in the population with SCI in the 2002 Guidelines for the Management of Acute Cervical Spine and Spinal Cord Injuries from the AANS and CNS. ${ }^{4,6}$

Testing for D-dimer, which is a marker of endogenous fibrinolysis, may play an important role in ruling out DVT, even though the current evidence does not support the general use of D-dimer testing as a stand-alone test for the diagnosis of DVT. ${ }^{45,103}$ In a randomized clinical trial, Wells and colleagues ${ }^{103}$ concluded that DVT can be ruled out and ultrasonography testing can be safely omitted in outpatients who are considered clinically unlikely to have DVT (as assessed by the Wells prediction score for DVT) and who have negative D-dimer test results. The Wells prediction score is a clinical model that can be used to predict the pretest probability of DVT in the general population using patients' symptoms, signs, and previous medical history. ${ }^{103}$ Based on the Wells prediction score, a diagnostic algorithm for DVT has recently been developed for application in the general population..$^{90}$ Given that the current guidelines recommend thromboprophylaxis during acute SCI, a validation study is required to determine the value of the Wells prediction score and the diagnostic algorithm in the specific group of patients with acute SCI.

Similar to the diagnosis of DVT, various diagnostic strategies for acute PE have been reported for the general population; these include diagnostic algorithms, which need to be validated for patients with acute SCI ${ }^{63,97,104}$ In brief, a suspected diagnosis of PE should be investigated by a careful assessment of the patient based on his or her medical history, physical examination results, and potential risk factors, including paralysis. ${ }^{97}$ In treating patients with a suspected PE, clinicians should also consider additional studies that include the ECG, chest radiography, arterial blood gas analysis, D-dimer testing, echocardiography, cardiac troponin level, and plasma concentration of brain natriuretic peptide, even though the results of these studies are usually not specific for PE. ${ }^{97}$ More specific imaging studies play a key role in the diagnosis of acute PE, including ventilation-perfusion scanning, contrast-enhanced CT arteriography, MR imaging, and standard pulmonary arteriography. ${ }^{97}$ In the absence of cardiopulmonary disease, ventilation-perfusion scanning is most likely to be diagnostic in patients with a suspected $\mathrm{PE}$, whereas a normal perfusion lung scan rules out acute PE. ${ }^{8,97}$ Contrast-enhanced CT arteriography has advantages over ventilation-perfusion scanning because it has a quicker acquisition, provides visualization of nonvascular structures, assesses the venous system for thrombosis, and can be performed simultaneously with CT venography for DVT. ${ }^{84,97}$

In a systematic review, Goodacre and colleagues ${ }^{44}$ studied the diagnostic role of noninvasive tests for proximal DVT and isolated calf DVT in patients with clinically suspected DVT and in high-risk asymptomatic patients. The authors concluded that, for the general population, diagnostic algorithms that combine the Wells prediction score, D-dimer test, and ultrasonography are among the most cost-effective diagnostic strategies. ${ }^{44}$ However, the development of an optimal diagnostic algorithm appropriate for a specific group at high risk for VTE, such as patients with acute $\mathrm{SCI}$, is recommended. ${ }^{4}{ }^{4}$

\section{Evidence-Based Prevention and Treatment of Cardiovascular Complications}

\section{Management of Cardiac and Hemodynamic Parameters After Acute SCI}

The impact of wider access to trauma centers and neurocritical care on mortality and disability after acute SCI is well recognized..$^{56}$ The most recent Clinical Practice Guidelines of the Consortium for Spinal Cord Medicine are focused on the most important clinical issues, including cardiovascular dysfunctions that can occur within the first 72 hours after acute SCI. ${ }^{20}$ Level II evidence supports the recommendation of transferring patients with acute SCI as soon as possible to a Level I trauma center as defined by the American College of Surgeons or by regional statute ${ }^{20}$ However, the 2002 AANS/CNS guidelines indicated that evidence supports only practice options, indicative of unclear clinical certainty, for treatment of patients with acute SCI in an intensive care unit or similarly monitored setting. ${ }^{5}$ Similarly, use of cardiac and hemodynamic monitoring equipment to detect cardiovascular dysfunction in patients with acute cervical SCI is recommended as a practice option in the 2002 AANS/CNS guidelines. ${ }^{5}$ Additional studies would likely support those recommendations in the level of guidelines and standards because the prevention and appropriate treatment of hemodynamic and cardiac irregularities can reduce mortality rates and improve neurological outcomes after acute SCI.

The Clinical Practice Guidelines of the Consortium for Spinal Cord Medicine reported that at least Level II evidence supports recommendations for the prevention and treatment of hypotension (systolic blood pressure < $90 \mathrm{~mm} \mathrm{Hg}$ ) with early appropriate fluid resuscitation, but with avoidance of volume overload, to maintain tissue 


\section{Cardiovascular complications in the acute stage after SCI}

perfusion and to resolve shock. ${ }^{20}$ The primary treatment for hypotension in patients with acute SCI is fluid resuscitation, even though there is currently no evidence for an appropriate resuscitation end point and optimal mean ABP that prevents hypotensive ischemia of the spinal cord ${ }^{20}$ Favorable outcomes were reported in uncontrolled studies that used clinical protocols including fluid resuscitation and use of vasopressive drugs to maintain a minimum mean ABP of $85 \mathrm{~mm} \mathrm{Hg}$ during the 1st week following SCI.65,100 Those recommendations agree with the status of practice options - which reflect unclear clinical certainty-in the management of acute SCI as indicated in the 2002 AANS/CNS guidelines. ${ }^{3,6}$ Indeed, the paucity of evidence indicates a need for further investigation to define optimal mean ABP and the role of pharmacological treatment for hypotension in patients with acute SCI. ${ }^{20}$

Although acute severe SCI at T-6 or a more cranial level is a major predisposing factor for neurogenic shock, Level III evidence with the highest level of panel agreement in the Consortium for Spinal Cord Medicine supports the recommendation for exclusion of other injuries prior to assigning the cause of hypotension to neurogenic shock. ${ }^{20}$ Similarly, the Consortium for Spinal Cord Medicine strongly recommended the clinical practice of timely diagnosis and appropriate treatment of neurogenic shock in the acute phase after SCI, whereas only Level III evidence was found to support this recommendation. ${ }^{20}$ In a nonsystematic review, Stevens and colleagues ${ }^{95}$ indicated that neurogenic shock should be treated with fluid resuscitation until intravascular volume is restored and, subsequently, use of vasopressors (such as dopamine, norepinephrine, and phenylephrine) may be required.

In addition to hypotension, persistent bradycardia is a common sign of neurogenic shock. Monitoring and treatment of symptomatic bradycardia after acute SCI received the highest level of panel agreement with recommendations based on Level III and Level IV evidence. ${ }^{20}$ To counter the loss of sympathetic tone and provide chronotropic cardiac support, vasopressors with both alphaand beta-adrenergic actions are recommended unless contraindicated. ${ }^{20}$

\section{Management of Acute Autonomic Dysreflexia After Acute SCI}

Although the Clinical Practice Guidelines of the Consortium for Spinal Cord Medicine for acute management of autonomic dysreflexia were published approximately a decade ago, this evidence-based set of recommendations remains relevant to clinical practice. ${ }^{2}$ The management of an individual with cervical or high-thoracic (T-6 or more cranial) level SCI with signs (including elevated blood pressure) and symptoms of autonomic dysreflexia is summarized in a clinical algorithm that includes monitoring of blood pressure and heart rate after each step. First, the individual should be immediately put in a sitting position if the person is supine. Second, clothing or constrictive devices need to be loosened. Third, potential triggers including bladder distension and bowel impaction should be investigated. If the systolic blood pressure is as elevated as $150 \mathrm{~mm} \mathrm{Hg}$ or higher, clinicians may consider pharma- cological management with a rapid-onset and short-duration antihypertensive agent (such as nifedipine or nitrates) prior to major additional sensory stimulation such as a rectal examination to reduce systolic blood pressure (but not cause hypotension). The resolution of the episode of autonomic dysreflexia should be followed by monitoring of symptoms, blood pressure, and heart rate for at least 2 hours to make sure it does not recur. However, if these management steps provide a poor response or the triggering of the autonomic dysreflexia is not determined, it is recommended to hospitalize the individual for monitoring and pharmacological control of blood pressure as well as further investigation of the potential triggering of the episode of autonomic dysreflexia.

\section{Management of VTE After Acute SCI}

Thromboprophylaxis is recognized as the standard of care for patients in the acute stage after SCI according to the evidence-based guidelines of the American College of Chest Physicians, of the AANS/CNS, and of the Consortium for Spinal Cord Medicine., ${ }^{4,20,21,42}$ There is Level I evidence to support the use of a mechanical method of prophylaxis such as a compression hose or pneumatic devices in both legs of all patients for at least the first 2 weeks after acute SCI. ${ }^{21,42}$ In addition to mechanical methods of prophylaxis, administration of an adjuvant thromboprophylactic drug within the first 72 hours is recommended when there is no evidence of active bleeding or coagulopathy. 4,20,21,42 Low-molecular-weight heparin is the first choice for pharmacological thromboprophylaxis in patients with acute SCI. ${ }^{4,20,2142}$ Alternatively, the guidelines of the American College of Chest Physicians recommend the use of intermittent pneumatic compression combined with either low-dose unfractionated heparin or low-molecular-weight heparin. ${ }^{42}$ An adjusted dose of unfractionated heparin appears as the second choice for pharmacological thromboprophylaxis in patients with acute SCI according to the guidelines of the Consortium for Spinal Cord Medicine. ${ }^{21}$ Also, at least Level II evidence supports the recommendation for individualized duration of the thromboprophylaxis depending on the patient's need, medical condition, functional status, support services, and risk. ${ }^{21}$ In patients with complete motor SCI without major clinical complications, anticoagulant prophylaxis is recommended for 8 weeks based on Level IV evidence. ${ }^{21} \mathrm{~A}$ more prolonged anticoagulant prophylaxis (12 weeks or until discharge from a rehabilitation setting) should be considered if a patient with complete motor SCI shows other risk factors for VTE including lower limb fracture, obesity, advanced age ( $>70$ years), heart failure, active cancer, or a previous history of thrombosis. ${ }^{21}$ Of note, the AANS/CNS guidelines recommend a 3-month duration of thromboprophylaxis as a practice option, which reflects unclear clinical certainty, based on the evidence in the literature. ${ }^{4}$ The use of an inferior vena cava filter is indicated only when pharmacological thromboprophylaxis has failed, there is a contraindication to anticoagulation (active bleeding), the patient's cardiopulmonary reserve is poor after complete motor high cervical (C-2 or C-3) SCI, or thrombosis in the inferior vena cava develops despite anticoagulant prophylaxis. , $^{3,7,42}$ 
A recent systematic review studied the role of screening tests for DVT in asymptomatic adults with acute SCI who undergo pharmacological thromboprophylaxis. ${ }^{36}$ In this group of patients, the current evidence is insufficient to support or refute a recommendation for routine screening. ${ }^{36}$ However, at least Level II evidence suggests that the use of a screening test might detect asymptomatic DVT in at least $9.4 \%$ of patients with acute SCI who undergo thromboprophylaxis with low-molecular-weight heparin during this acute stage. ${ }^{36}$ In another recently published systematic review of 45 selected studies, Goodacre and colleagues ${ }^{44}$ indicated that all of the diagnostic tests showed a poorer performance in asymptomatic patients because thrombi in those individuals are likely to be smaller and more distal. However, only a few studies have focused on asymptomatic patients who undergo anticoagulant prophylaxis during the acute stage after SCI. ${ }^{44}$ Also, the efficacy of the evidence-based guidelines in the prevention of VTE might be underestimated due to several barriers against their implementation. ${ }^{15,110}$ Using data from the HealthFacts database in the United States, $\mathrm{Yu}$ and colleagues ${ }^{110}$ reported that only $4(9.1 \%)$ of 44 patients with acute SCI who were admitted to a hospital between January 2001 and March 2005 received a guideline-recommended type of prophylaxis. Among the 40 noncompliant patients, 31 (77.5\%) received no prophylaxis and 9 received some prophylaxis for an inadequate duration. ${ }^{110}$ Similarly, Burns and colleagues ${ }^{15}$ found that publication and implementation of guidelines for prevention of VTE among patients with SCI had a modest effect on practice in 6 Veterans Affairs SCI medical centers.

When a patient is diagnosed with VTE, pharmacological treatment is required unless there is a serious contraindication. To reduce the risk of recurrent DVT, postthrombotic syndrome, and development of PE, intravenous or subcutaneous heparin therapy should be immediately initiated and, subsequently, replaced by treatment with oral warfarin for a period of time ranging from 6 weeks to 6 months. ${ }^{46,57}$ Given that the use of anticoagulation treatment involves a relatively significant risk of hemorrhage, clinicians need to weigh the potential benefits and risks for each patient in the process of decision making. 44,67

When acute PE is diagnosed, the patient should be treated with parenteral anticoagulation therapy unless it is contraindicated ${ }^{97}$ Subcutaneous administration of lowmolecular-weight heparin or the pentasaccharide fondaparinux (a highly selective indirect inhibitor of factor Xa) or intravenous unfractionated heparin is recommended for the first 5 days in patients with a diagnosis of $\mathrm{PE}$ (or even in patients with a high suspicion of PE if the risk of bleeding is not excessive) until the international normalized ratio is in the therapeutic range of 2.0 to 3.0 for 2 consecutive days. ${ }^{97}$ If standard heparin is the primary anticoagulant drug, a therapeutic range from 1.5 to 2.5 times control for activated partial thromboplastin time is targeted ${ }^{97}$ After reaching a consistent therapeutic range with a parenteral anticoagulant, only oral warfarin that was initiated on the 1st day of anticoagulant therapy and maintained for 6 months should be sufficient to treat the PE and prevent complications and other thromboembolic events. ${ }^{97}$

\section{Conclusions}

Cardiovascular complications commonly occur following severe SCI. Loss of supraspinal control of the SNS is the major cause of cardiac dysfunction and hemodynamic instability in patients following SCI. These physiological changes are much more common in individuals with complete motor SCI at or rostral to T-6. The most common cardiovascular dysfunctions following acute SCI include supine and orthostatically induced hypotension, autonomic dysreflexia, and cardiac arrhythmias (including persistent bradycardia). Evidence-based guidelines emphasize 4 key interventions to minimize the deleterious effects of cardiovascular dysfunction following acute SCI: 1) monitoring of cardiac and hemodynamic parameters in the acute phase; 2) maintenance of a minimum mean $\mathrm{ABP}$ of $85 \mathrm{~mm} \mathrm{Hg}$; 3) timely detection and appropriate treatment of neurogenic shock and cardiac arrhythmias; and 4) immediate and adequate treatment of episodes of acute autonomic dysreflexia.

In addition to cardiovascular dysfunction, individuals with acute SCI are at increased risk for VTE due to immobilization (stasis) and, potentially, altered fibrinolytic activity, abnormal platelet function, and impaired circadian variations of hemostatic and fibrinolytic parameters. Current evidence strongly supports the recommendations for thromboprophylaxis using mechanical methods and anticoagulants during the acute stage up to 3 months following SCI, depending on the severity and level of injury. Low-molecular-weight heparin is the first choice for anticoagulant prophylaxis in patients with acute SCI. When DVT or PE is diagnosed, prompt initiation of heparin is usually required unless there is a serious contraindication. Clinicians need to maintain a heightened awareness of cardiovascular dysfunction following acute SCI to intervene proactively and optimize clinical outcomes.

\section{Disclaimer}

The authors report no conflict of interest concerning the materials or methods used in this study or the findings specified in this paper.

\section{Acknowledgments}

This work was supported by the Krembil Chair in Neural Repair and Regeneration, Toronto Western Research Institute and University of Toronto, held by Michael G. Fehlings, M.D., Ph.D., F.R.C.S.C.

\section{References}

1. Anderson FA Jr, Spencer FA: Risk factors for venous thromboembolism. Circulation 107:I9-I16, 2003

2. Anonymous: Acute management of autonomic dysreflexia: adults with spinal cord injury presenting to health-care facilities. J Spinal Cord Med 20:284-308, 1997

3. Anonymous: Blood pressure management after acute spinal cord injury. Neurosurgery 50:S58-S62, 2002

4. Anonymous: Deep venous thrombosis and thromboembolism in patients with cervical spinal cord injuries. Neurosurgery 50:S73-S80, 2002

5. Anonymous: Management of acute spinal cord injuries in an intensive care unit or other monitored setting. Neurosurgery 50:S51-S57, 2002 


\section{Cardiovascular complications in the acute stage after SCI}

6. Anonymous: Methodology of guideline development. Neurosurgery 50:S2-S6, 2002

7. Anonymous: Prevention of venous thromboembolism in the acute treatment phase after spinal cord injury: a randomized, multicenter trial comparing low-dose heparin plus intermittent pneumatic compression with enoxaparin. Spinal Cord Injury Thromboprophylaxis Investigators. J Trauma 54:1116-1116, 2003

8. Anonymous: Value of the ventilation/perfusion scan in acute pulmonary embolism. Results of the prospective investigation of pulmonary embolism diagnosis (PIOPED). The PIOPED Investigators. JAMA 263:2753-2759, 1990

9. Appenzeller O, Oribe E: Autonomic anatomy, histology and neurotransmission, in Appenzeller O, Oribe E (ed): The Autonomic Nervous System: An Introduction to Basic and Clinical Concepts, ed 5. New York: Elsevier, 1997, pp 2-8

10. Atkinson PP, Atkinson JL: Spinal shock. Mayo Clin Proc 71:384-389, 1996

11. Badoer E, McKinlay D, Trigg L, et al: Distribution of activated neurons in the rabbit brain following a volume load. Neuroscience 81:1065-1077, 1997

12. Bainbridge FA: The influence of venous filling upon the rate of the heart. J Physiol 50:65-84, 1915

13. Bonica JJ: Autonomic innervation of the viscera in relation to nerve block. Anesthesiology 29:793-813, 1968

14. Bunten DC, Warner AL, Brunnemann SR, et al: Heart rate variability is altered following spinal cord injury. Clin Auton Res 8:329-334, 1998

15. Burns SP, Nelson AL, Bosshart HT, et al: Implementation of clinical practice guidelines for prevention of thromboembolism in spinal cord injury. J Spinal Cord Med 28:33-42, 2005

16. Cao WH, Fan W, Morrison SF: Medullary pathways mediating specific sympathetic responses to activation of dorsomedial hypothalamus. Neuroscience 126:229-240, 2004

17. Centers for Disease Control and Prevention: Spinal Cord Injury Facts. Atlanta, GA: National Center for Injury Prevention and Control, 2006 (http://www.cdc.gov/ncipc/factsheets/ scifacts.htm) [Accessed 30 September 2008]

18. Cleophas TJ, Kauw FH, Bijl C, et al: Effects of beta adrenergic receptor agonists and antagonists in diabetics with symptoms of postural hypotension: a double-blind, placebo-controlled study. Angiology 37:855-862, 1986

19. Collins HL, Rodenbaugh DW, DiCarlo SE: Spinal cord injury alters cardiac electrophysiology and increases the susceptibility to ventricular arrhythmias. Prog Brain Res 152:275-288, 2006

20. Consortium for Spinal Cord Medicine: Early acute management in adults with spinal cord injury: a clinical practice guideline for health-care providers. Washington, DC: Paralyzed Veterans of America, 2008 (http://www.pva.org/ site/DocServer/57462_PVA.pdf?docID=5181 ) [Accessed 30 September 2008]

21. Consortium for Spinal Cord Medicine: Prevention of thromboembolism in spinal cord injury, ed 2. Washington, DC: Paralyzed Veterans of America, 1999(http://www.pva.org/ site/DocServer/DVT.pdf?docID=644 ) [Accessed 30 September 2008]

22. Coote JH: A role for the paraventricular nucleus of the hypothalamus in the autonomic control of heart and kidney. Exp Physiol 90:169-173, 2005

23. Dahlberg A, Kotila M, Leppanen P, et al: Prevalence of spinal cord injury in Helsinki. Spinal Cord 43:47-50, 2005

24. Deng Y, Kaufman S: Effect of pregnancy on activation of central pathways following atrial distension. Am J Physiol 269:R552-R556, 1995

25. Desaulles E, Reiter MK, Feltz P: Electrophysiological evidence for oxytocin receptors on sympathetic preganglionic neurones - an in vitro study on the neonatal rat. Brain Res 699:139-142, 1995

26. Ditunno JF, Little JW, Tessler A, et al: Spinal shock revisited: a four-phase model. Spinal Cord 42:383-395, 2004

27. Downey J, Myers SJ, Gonzalez EG, et al: The Physiological Basis of Rehabilitation Medicine, ed 2. Oxford: Butterworth-Heinemann, 1994

28. Elenkov IJ, Wilder RL, Chrousos GP, et al: The sympathetic nerve-an integrative interface between two supersystems: the brain and the immune system. Pharmacol Rev 52:595-638, 2000

29. Evans DE, Kobrine AI, Rizzoli HV: Cardiac arrhythmias accompanying acute compression of the spinal cord. J Neurosurg 52:52-59, 1980

30. Fehlings MG, Vaccaro A, Aarabi B, et al: A prospective, multicenter trial to evaluate the role and timing of decompression in patients with cervical spinal cord injury: initial one year results of the STASCIS study. J Neurosurg 108:A848, 2008 (Abstract)

31. Fontes MA, Tagawa T, Polson JW, et al: Descending pathways mediating cardiovascular response from dorsomedial hypothalamic nucleus. Am J Physiol Heart Circ Physiol 280: H2891-H2901, 2001

32. Foreman RD, Wurster RD: Localization and functional characteristics of descending sympathetic spinal pathways. Am J Physiol 225:212-217, 1973

33. Frisbie JH, Steele DJ: Postural hypotension and abnormalities of salt and water metabolism in myelopathy patients. Spinal Cord 35:303-307, 1997

34. Fujii Y, Mammen EF, Farag A, et al: Thrombosis in spinal cord injury. Thromb Res 68:357-368, 1992

35. Furlan JC, Bracken MB, Fehlings MG: Is age a key determinant of mortality and neurological outcome after acute traumatic spinal cord injury? Neurobiol Aging [epub ahead of print] 2008

36. Furlan JC, Fehlings MG: Role of screening tests for deep venous thrombosis in asymptomatic adults with acute spinal cord injury: an evidence-based analysis. Spine 32:1908-1916, 2007

37. Furlan JC, Fehlings MG, Shannon P, et al: Descending vasomotor pathways in humans: correlation between axonal preservation and cardiovascular dysfunction after spinal cord injury. J Neurotrauma 20:1351-1363, 2003

38. Furlan JC, Krassioukov AV, Fehlings MG: Hematologic abnormalities within the first week after acute isolated traumatic cervical spinal cord injury: a case-control cohort study. Spine 31:2674-2683, 2006

39. Garshick E, Kelley A, Cohen SA, et al: A prospective assessment of mortality in chronic spinal cord injury. Spinal Cord 43:408-416, 2005

40. Garstang SV, Miller-Smith SA: Autonomic nervous system dysfunction after spinal cord injury. Phys Med Rehabil Clin N Am 18:275296, 2007

41. Geerts WH, Code KI, Jay RM, et al: A prospective study of venous thromboembolism after major trauma. $\mathbf{N}$ Engl J Med 331:1601-1606, 1994

42. Geerts WH, Pineo GF, Heit JA, et al: Prevention of venous thromboembolism: the Seventh ACCP Conference on Antithrombotic and Thrombolytic Therapy. Chest 126:338S400S, 2004

43. Glenn MB, Bergman SB: Cardiovascular changes following spinal cord injury. Top Spinal Cord Inj Rehabil 2:47-53, 1997

44. Goodacre S, Sampson F, Stevenson M, et al: Measurement of the clinical and cost-effectiveness of non-invasive diagnostic testing strategies for deep vein thrombosis. Health Technol Assess 10:1168, 2006

45. Heim SW, Schectman JM, Siadaty MS, et al: D-dimer testing for deep venous thrombosis: a metaanalysis. Clin Chem 50:1136-1147, 2004 
46. Hirsh J, Bates SM: Clinical trials that have influenced the treatment of venous thromboembolism: a historical perspective. Ann Intern Med 134:409-417, 2001

47. Horiuchi J, McAllen RM, Allen AM, et al: Descending vasomotor pathways from the dorsomedial hypothalamic nucleus: role of medullary raphe and RVLM. Am J Physiol Regul Integr Comp Physiol 287:R824-R832, 2004

48. Horiuchi J, McDowall LM, Dampney RA: Differential control of cardiac and sympathetic vasomotor activity from the dorsomedial hypothalamus. Clin Exp Pharmacol Physiol 33:1265-1268, 2006

49. Illman A, Stiller K, Williams M: The prevalence of orthostatic hypotension during physiotherapy treatment in patients with an acute spinal cord injury. Spinal Cord 38:741-747, 2000

50. Iversen PO, Groot PD, Hjeltnes N, et al: Impaired circadian variations of haemostatic and fibrinolytic parameters in tetraplegia. Br J Haematol 119:1011-1016, 2002

51. Johnson CD, Perea Lopez RM, Rodriguez L: Acute spinal cord and head injury: case report and discussion of cardiac, respiratory and endocrine abnormalities. Bol Asoc Med P R 90:95-101, 1998

52. Kappagoda CT, Linden RJ, Scott EM, et al: Atrial receptors and heart rate: the efferent pathway. J Physiol 249:581-590, 1975

53. Karim F, Kidd C, Malpus CM, et al: The effects of stimulation of the left atrial receptors on sympathetic efferent nerve activity. J Physiol 227:243-260, 1972

54. Kaufman S, Deng Y: Renal response to atrial stretch during pregnancy in conscious rats. Am J Physiol 265:R902-R906, 1993

55. Kaufman S, Mackay B, Kappagoda CT: Effect of stretching the superior vena cava on heart rate in rats. Am J Physiol 241:H248-H254, 1981

56. Kelly DF, Becker DP: Advances in management of neurosurgical trauma: USA and Canada. World J Surg 25:1179-1185, 2001

57. Kelly J, Hunt BJ: Do anticoagulants improve survival in patients presenting with venous thromboembolism? J Intern Med 254:527-539, 2003

58. Kerr FW, Alexander S: Descending autonomic pathways in the spinal cord. Arch Neurol 10:249-261, 1964

59. Kidd C: Central neuron activation by cardiac receptors, in Hainsworth R, Kidd C, Linden RJ (eds): Cardiac Receptors. London: Cambridge University Press, 1979, pp 377-403

60. Kopp UC, Smith LA, DiBona GF: Facilitatory role of efferent renal nerve activity on renal sensory receptors. Am J Physiol 253:F767-F777, 1987

61. Krassioukov A, Claydon VE: The clinical problems in cardiovascular control following spinal cord injury: an overview. Prog Brain Res 152:223-229, 2006

62. Krassioukov AV, Furlan JC, Fehlings MG: Autonomic dysreflexia in acute spinal cord injury: an under-recognized clinical entity. J Neurotrauma 20:707-716, 2003

63. Le Gal G, Righini M, Roy PM, et al: Prediction of pulmonary embolism in the emergency department: the revised Geneva score. Ann Intern Med 144:165-171, 2006

64. Lehmann KG, Lane JG, Piepmeier JM, et al: Cardiovascular abnormalities accompanying acute spinal cord injury in humans: incidence, time course and severity. J Am Coll Cardiol 10:46-52, 1987

65. Levi L, Wolf A, Belzberg H: Hemodynamic parameters in patients with acute cervical cord trauma: description, intervention, and prediction of outcome. Neurosurgery 33:1007-1017, 1993

66. Lindan R, Joiner E, Freehafer AA, et al: Incidence and clinical features of autonomic dysreflexia in patients with spinal cord injury. Paraplegia 18:285-292, 1980

67. Linkins LA, Choi PT, Douketis JD: Clinical impact of bleeding in patients taking oral anticoagulant therapy for ve- nous thromboembolism: a meta-analysis. Ann Intern Med 139:893-900, 2003

68. Linsenmeyer TA, Campagnolo DI, Chou IH: Silent autonomic dysreflexia during voiding in men with spinal cord injuries. J Urol 155:519-522, 1996

69. Loewy AD, Spyer KM (eds): Central Regulation of Autonomic Functions. New York: Oxford University Press, 1990

70. Lovick TA, Coote JH: Circulating atrial natriuretic factor activates vagal afferent inputs to paraventriculo-spinal neurones in the rat. J Auton Nerv Syst 26:129-134, 1989

71. Lovick TA, Coote JH: Effects of volume loading on paraventriculo-spinal neurones in the rat. J Auton Nerv Syst 25:135140,1988

72. Lovick TA, Coote JH: Electrophysiological properties of paraventriculo-spinal neurones in the rat. Brain Res 454:123130,1988

73. Maiorov DN, Fehlings MG, Krassioukov AV: Relationship between severity of spinal cord injury and abnormalities in neurogenic cardiovascular control in conscious rats. J Neurotrauma $15: 365-374,1998$

74. Mathias CJ: Orthostatic hypotension and paroxysmal hypertension in humans with high spinal cord injury. Prog Brain Res 152:231-243, 2006

75. Mathias CJ: Orthostatic hypotension: causes, mechanisms, and influencing factors. Neurology 45:S6-S11, 1995

76. Mathias CJ, Frankel HL: The cardiovascular system in tetraplegia and paraplegia, in Frankel HL (ed): Handbook of Clinical Neurology: Spinal Cord Trauma, Vol 17. Amsterdam: Elsevier, 1992, pp 435-456

77. Merli GJ, Crabbe S, Paluzzi RG, et al: Etiology, incidence, and prevention of deep vein thrombosis in acute spinal cord injury. Arch Phys Med Rehabil 74:1199-1205, 1993

78. Miranda AR, Hassouna HI: Mechanisms of thrombosis in spinal cord injury. Hematol Oncol Clin North Am 14:401-416, 2000

79. Mohrman D, Heller L: Regulation of arterial pressure, in Mohrman D, Heller L (eds): Cardiovaslcular Physiology. New York: McGraw-Hill, 2006, pp 157-180

80. Munakata M, Kameyama J, Kanazawa M, et al: Circadian blood pressure rhythm in patients with higher and lower spinal cord injury: simultaneous evaluation of autonomic nervous activity and physical activity. J Hypertens 15:1745-1749, 1997

81. Myers J, Lee M, Kiratli J: Cardiovascular disease in spinal cord injury: an overview of prevalence, risk, evaluation, and management. Am J Phys Med Rehabil 86:142-152, 2007

82. Nalivaiko E, Ootsuka Y, Blessing WW: Activation of 5-HT1A receptors in the medullary raphe reduces cardiovascular changes elicited by acute psychological and inflammatory stresses in rabbits. Am J Physiol Regul Integr Comp Physiol 289:R596-R604, 2005

83. O'Connor PJ: Prevalence of spinal cord injury in Australia. Spinal Cord 43:42-46, 2005

84. Orbell JH, Smith A, Burnand KG, et al: Imaging of deep vein thrombosis. Br J Surg 95:137-146, 2008

85. Piepmeier JM, Lehmann KB, Lane JG: Cardiovascular instability following acute cervical spinal cord trauma. Cent Nerv Syst Trauma 2:153-160, 1985

86. Pyner S, Coote JH: Identification of branching paraventricular neurons of the hypothalamus that project to the rostroventrolateral medulla and spinal cord. Neuroscience 100:549-556, 2000

87. Pyner S, Deering J, Coote JH: Right atrial stretch induces renal nerve inhibition and c-fos expression in parvocellular neurones of the paraventricular nucleus in rats. Exp Physiol 87:25-32, 2002

88. Rossi EC, Green D, Rosen JS, et al: Sequential changes in factor VIII and platelets preceding deep vein thrombosis in patients with spinal cord injury. Br J Haematol 45:143-151, 1980 


\section{Cardiovascular complications in the acute stage after SCI}

89. Samuels BC, Zaretsky DV, DiMicco JA: Tachycardia evoked by disinhibition of the dorsomedial hypothalamus in rats is mediated through medullary raphe. J Physiol 538:941-946, 2002

90. Scarvelis D, Wells PS: Diagnosis and treatment of deep-vein thrombosis. CMAJ 175: 1087-1092, 2006

91. Sclater A, Alagiakrishnan K: Orthostatic hypotension. A primary care primer for assessment and treatment. Geriatrics 59:22-27, 2004

92. Sermasi E, Coote JH: Oxytocin acts at V1 receptors to excite sympathetic preganglionic neurones in neonate rat spinal cord in vitro. Brain Res 647:323-332, 1994

93. Shafton AD, Ryan A, Badoer E: Neurons in the hypothalamic paraventricular nucleus send collaterals to the spinal cord and to the rostral ventrolateral medulla in the rat. Brain Res 801:239243, 1998

94. Silver JR: Early autonomic dysreflexia. Spinal Cord 38:229233, 2000

95. Stevens RD, Bhardwaj A, Kirsch JR, et al: Critical care and perioperative management in traumatic spinal cord injury. $\mathbf{J}$ Neurosurg Anesthesiol 15:215-229, 2003

96. Strack AM, Sawyer WB, Hughes JH, et al: A general pattern of CNS innervation of the sympathetic outflow demonstrated by transneuronal pseudorabies viral infections. Brain Res 491:156-162, 1989

97. Tapson VF: Acute pulmonary embolism. N Engl J Med 358:1037-1052, 2008

98. Teasell RW, Arnold JM, Krassioukov A, et al: Cardiovascular consequences of loss of supraspinal control of the sympathetic nervous system after spinal cord injury. Arch Phys Med Rehabil 81:506-516, 2000

99. Tuli S, Tuli J, Coleman WP, et al: Hemodynamic parameters and timing of surgical decompression in acute cervical spinal cord injury. J Spinal Cord Med 30:482-490, 2007

100. Vale FL, Burns J, Jackson AB, et al: Combined medical and surgical treatment after acute spinal cord injury: results of a prospective pilot study to assess the merits of aggressive medical resuscitation and blood pressure management. J Neurosurg 87:239-246, 1997

101. Vaziri ND: Nitric oxide in microgravity-induced orthostatic intolerance: relevance to spinal cord injury. J Spinal Cord Med 26:5-11, 2003

102. Wecht JM, De Meersman RE, Weir JP, et al: Cardiac autonomic responses to progressive head-up tilt in individuals with paraplegia. Clin Auton Res 13:433-438, 2003

103. Wells PS, Anderson DR, Rodger M, et al: Evaluation of D-dimer in the diagnosis of suspected deep-vein thrombosis. N Engl J Med 349:1227-1235, 2003

104. Wells PS, Anderson DR, Rodger M, et al: Excluding pulmonary embolism at the bedside without diagnostic imaging: management of patients with suspected pulmonary embolism presenting to the emergency department by using a simple clinical model and d-dimer. Ann Intern Med 135:98-107, 2001

105. Winslow EB, Lesch M, Talano JV, et al: Spinal cord injuries associated with cardiopulmonary complications. Spine 11:809812,1986

106. Winther K, Gleerup G, Snorrason K, et al: Platelet function and fibrinolytic activity in cervical spinal cord injured patients. Thromb Res 65:469-474, 1992

107. Wyndaele M, Wyndaele JJ: Incidence, prevalence and epidemiology of spinal cord injury: what learns a worldwide literature survey? Spinal Cord 44:523-529, 2006

108. Yang Z, Wheatley M, Coote JH: Neuropeptides, amines and amino acids as mediators of the sympathetic effects of paraventricular nucleus activation in the rat. Exp Physiol 87:663-674, 2002

109. Yao JS: Deep vein thrombosis in spinal cord-injured patients. Evaluation and assessment. Chest 102:645S-648S, 1992

110. Yu HT, Dylan ML, Lin J, et al: Hospitals' compliance with prophylaxis guidelines for venous thromboembolism. Am J Health Syst Pharm 64:69-76, 2007

Manuscript submitted July 10, 2008.

Accepted September 22, 2008.

Address correspondence to: Michael G. Fehlings, M.D., Ph.D., F.R.C.S.C., Toronto Western Hospital, 399 Bathurst Street, 4W449, Toronto, Ontario, Canada, M5T 2S8. email: michael.fehlings@uhn. on.ca. 